\title{
Better pathological tumor characteristics might occur in recurrent metastatic breast cancer patients after 10-year metastatic free interval
}

\author{
Kadri Altundag ${ }^{1}$ (D) \\ Received: 8 October 2018 / Accepted: 12 October 2018 / Published online: 15 October 2018 \\ ○) Springer Science+Business Media, LLC, part of Springer Nature 2018
}

\section{Dear Editor,}

I want to congratulate Chang and their colleagues for their article [1] in which they investigated the association between metastatic free interval (MFI) and subsequent survival from newly diagnosed metastatic breast cancer (MBC) in a population-level US cohort. They reported that prolonged MFI greater than 10 years between initial breast cancer diagnosis and subsequent metastatic disease was found to be associated with improved recurrent MBC 5-year survival and decreased risk of breast cancer-specific mortality. However, the authors did not provide detailed information about the association of immunohistochemical receptor status between primary and recurrent metastatic tumors. A change of estrogen receptor, progesterone receptor, and HER2 status in recurrent metastatic tumors has frequently been reported. The actual incidence of this phenomenon has been debated. Recent meta-analysis including 39 studies assessing receptor conversion from primary breast tumors to paired distant breast cancer metastases showed that negative to positive conversion percentages were $21.5 \%, 15.9 \%$, and $9.5 \%$ for estrogen receptor, progesterone receptor, and HER2, respectively. In this study, the authors did not look at any association between discordant rate and MFI [2]. In conclusion, better pathological tumor characteristics might occur in recurrent MBC patients after 10-year MFI. This issue merits further investigation.

\section{Compliance with ethical standards}

Conflict of interest Author has no conflict of interest to declare. The author has not received any grants.

Research involving human and animal participants This article does not contain any studies with human participants or animals performed by any of the authors.

\section{References}

1. Chang E, Mougalian SS, Adelson KB, Young MR, Yu JB (2018) Association between prolonged metastatic free interval and recurrent metastatic breast cancer survival: findings from the SEER database. Breast Cancer Res Treat. https://doi.org/10.1007/s1054 9-018-4968-7. (Epub ahead of print)

2. Schrijver WAME, Suijkerbuijk KPM, van Gils CH et al (2018) Receptor conversion in distant breast cancer metastases: a systematic review and meta-analysis. J Natl Cancer Inst 110(6):568-580
Kadri Altundag

altundag66@yahoo.com

1 MKA Breast Cancer Clinic, Tepe Prime, Cankaya, 06800 Ankara, Turkey 